\title{
A Comparison of the Performance and Stability of Pd/BCC Metal Composite Membranes for Hydrogen Purification
}

Daniel A. Cooney ${ }^{\mathrm{a}}$, J. Douglas Way ${ }^{\mathrm{a}}$, and Colin A. Wolden ${ }^{\mathrm{a},{ }^{*}}$

a. Colorado School of Mines, Department of Chemical and Biological Engineering, 1600 Illinois Street, Golden, CO 80401 USA

\begin{abstract}
Composite membranes were fabricated by sputtering $100 \mathrm{~nm}$ of Pd on to both sides of dense BCC metal foils $(\mathrm{V}, \mathrm{Ta}, \mathrm{Nb})$. Under pure $\mathrm{H}_{2}$ gas testing at $500{ }^{\circ} \mathrm{C}$ the maximum permeability of all three metals exceeds previously reported values and closely approach theoretical limits. However, the stability of each membrane varied significantly due to unique failure mechanisms. $\mathrm{Pd} / \mathrm{V}$ membranes failed quickly ( $<20$ hours) due to a combination of $\mathrm{Pd}-\mathrm{V}$ interdiffusion and high susceptibility to oxidation as shown through microscopy and compositional analysis. The $\mathrm{Pd} / \mathrm{Ta}$ membranes were the most resilient to oxygen, but their mechanical integrity was relatively poor and they failed within 48 hours due to $\mathrm{Pd}-\mathrm{Ta}$ interdiffusion. In contrast, $\mathrm{Pd} / \mathrm{Nb}$ membranes exhibited high permeability throughout the 168 hours of testing, with no Pd-Nb interdiffusion observed. The decline in permeability observed during testing was attributed to partial Pd delamination as a result of membrane deformation. These results provide pathways for further development of these membranes.
\end{abstract}

Keywords: Hydrogen separation; BCC metal membrane; vanadium; niobium; tantalum;

\footnotetext{
* Corresponding author. Colorado School of Mines Chemical and Biological Engineering, 1600 Illinois St., Golden, CO 80401, Phone: (303) 273-3544, FAX: (303) 273-3730. Email: cwolden@mines.edu
} 


\section{Introduction}

Over $95 \%$ of usable $\mathrm{H}_{2}$ is produced from fossil fuels such as natural gas or coal through steam reforming [1]. These processes produce a mixture of gases including $\mathrm{H}_{2}, \mathrm{CO}, \mathrm{CO}_{2}$, and $\mathrm{H}_{2} \mathrm{O}$, requiring an extensive series of separation processes to produce high purity hydrogen. Current technologies such as cryogenic separation and pressure swing adsorption are both energy and capital intensive [2]. Hydrogen selective membranes could offer a cost effective and practical alternative to these technologies [3].

Palladium is an excellent $\mathrm{H}_{2}$ permeable material because of its relatively high atomic hydrogen solubility in its face centered cubic (FCC) lattice structure, and its ability to efficiently dissociate $\mathrm{H}_{2}$ into atomic hydrogen. These unique attributes are why membranes comprised of palladium and its alloys membranes dominate academic and industrial research $[4,5]$. While these properties make $\mathrm{Pd}$ an attractive $\mathrm{H}_{2}$ separation material, it's extremely high and volatile cost constrains widespread deployment of these technologies. Furthermore, to make cost effective and high permeance Pd membranes, films of Pd less than 20 microns in thickness are required, which are prone to defects and pinholes leading to lower purity hydrogen [6].

The group- $\mathrm{V}$ transition metals $(\mathrm{V}, \mathrm{Nb}$, and $\mathrm{Ta}$ ) have theoretically higher atomic hydrogen permeability than Pd [7], a feature that has been demonstrated experimentally in a number of systems $[8,9,10,11]$. The high permeability of these metals is attributed to their more open BCC lattice structure that allows for greater hydrogen solubility and more rapid diffusion. Additionally, the costs of these metals are more than an order of magnitude lower than that of

pure Pd. Because of the high $\mathrm{H}_{2}$ permeability and low cost of these BCC metals, thicker layers and cold rolled foils can be used which are mechanical robust and offer infinite selectivity. 
The challenge with these metals comes from the fact, that unlike Pd, they have little or no ability to catalytically dissociate $\mathrm{H}_{2}$ into atomic hydrogen, the state in which it can be transported through the BCC lattice [12]. To overcome this limitation films of various $\mathrm{H}_{2}$ dissociation catalysts can be added to the feed and permeate surfaces of these BCC transition metals to facilitate hydrogen dissociation and recombination $[13,14]$. Thin films of Pd of varying thickness have been investigated for these purposes using different methods of deposition $[9,10,11]$. Commonly used techniques for application of Pd include physical vapor deposition methods such as sputtering [15] or solution approaches such as electro- or electroless plating [4]. The group V metals tend to form a native oxide, which impedes hydrogen transport, so special precautions such as chemical or ion etching must be taken before deposition of a catalyst layer $[9,16]$.

There are two failure modes for $\mathrm{Pd} / \mathrm{BCC}$ composite membranes that are commonly reported. At temperatures below $350^{\circ} \mathrm{C}$ hydrogen embrittlement can occur, causing these membranes to break $[17,18]$. Hydrogen embrittlement at low temperature is thought to be due to the increase solubility of hydrogen in each of the BCC metals at low temperature. To mitigate these effects alloys have been prepared that reduce the solubility of hydrogen in the membrane material and limit embrittlement $[14,19,20]$. Above $350^{\circ} \mathrm{C}$ membrane failure mechanisms are due to a loss of catalytic activity through mechanisms such as Pd interdiffusion with the BCC metal [16,21] or Pd agglomeration and fragmentation [11,22,23,24,25]. While this work has furthered the possibility of using group $\mathrm{V}$ transition metal-based membranes in an industrial setting, most reports have focused on a single metal, and making direct comparisons among the three metals somewhat difficult. Further complicating comparisons is the significant variability in both the thickness of the Pd catalyst layer and its method of deposition, as well as the conditions used 
during permeation testing. Furthermore, while the work of Buxbaum [9,10], Rothenberger [11], Peachey [16] and other have all achieved high permeability using these metals, the reported values have fallen short of the theoretical permeability of these materials as calculated by Steward in 1986 [7].

Herein we report direct side-by-side comparisons of Pd coated V, Ta, and $\mathrm{Nb}$ membranes all exposed to the same conditions with identical catalyst layers. Electron microscopy and compositional analysis performed before and after membrane testing are used to investigate the mechanisms involved in degradation. It is shown that each material closely approached the theoretical limits of permeability, but displayed very different stability behavior.

\section{Experimental}

\subsection{Membrane fabrication}

BCC composite membranes were fabricated from free standing foils of cold rolled vanadium (50 micron thickness, $99.9 \%$ purity), tantalum (100 micron thickness, 99.9\% purity), and niobium (100 micron thickness, 99.98\% purity) purchased from ESPI metals. The difference in thickness was due to the mechanical strength of the materials. As discussed below, the Ta and Nb-based membranes undergo mechanical deformation during $\mathrm{H}_{2}$ permeation testing. Membranes fabricated from $50 \mu \mathrm{m}$ foils would often break, an issue that was resolved by using $100 \mu \mathrm{m}$ foils. In contrast, the $\mathrm{V}$ membranes undergo no visible deformation and are mechanically quite robust so $50 \mu \mathrm{m}$ foils were used to maximize permeance. $100 \mathrm{~nm}$ Pd catalytic layers were deposited using an AJA Orion sputtering system. This layer thickness was chosen to provide efficient catalytic activity but not pose any significant transport resistance. Native oxides were first removed from the BCC surface via a pre-deposition in situ Ar sputter treatment. This was 
accomplished by applying $100 \mathrm{~W}$ RF power to the substrate susceptor, which produced a plasma with an approximate $490 \mathrm{~V}$ DC bias. The $100 \mathrm{~nm}$ thick Pd catalytic layer was subsequently deposited without breaking high vacuum via DC sputtering by applying a 0.1 A current to a 2 in. diameter Pd target, which an applied voltage of $300 \mathrm{~V}$. The distance between the Pd target and the rotating $\mathrm{BCC}$ metal substrate was fixed at $8 \mathrm{~cm}$ and the resulting deposition rate was 7 $\mathrm{nm} / \mathrm{min}$ as determined by profilometry. Samples were then removed from the sputter system, turned over, and the process was repeated to form symmetric composite membranes.

\section{$2.2 \quad \mathrm{H}_{2}$ permeation measurements}

The fabricated membranes were sealed in commercial VCR fittings leaving an exposed area of $0.93 \mathrm{~cm}^{2}$. Membranes were heated to $500^{\circ} \mathrm{C}$ at $2^{\circ} \mathrm{C} / \mathrm{min}$ under ultra high purity $\mathrm{He}$ to avoid $\mathrm{H}_{2}$ embrittlement. The membranes were then tested at $500{ }^{\circ} \mathrm{C}$ by delivering pure $\mathrm{H}_{2}$ gas $(99.9 \%)$ to the feed side of the membrane. The temperature of $500{ }^{\circ} \mathrm{C}$ for testing was selected for two reasons. First, this temperature is high enough to minimize issues related to hydrogen embrittlement. Second, it is known that interdiffusion between BCC metals and Pd becomes significant at $\mathrm{T}>400{ }^{\circ} \mathrm{C}[26]$, and this temperature combined with the use of relatively thin $\mathrm{Pd}$ layers allowed membrane failure to be documented within reasonable time scales. The feed pressure was kept between 5 and 10 psig via a back pressure regulator located in the retentate line. Permeate flow was collected at ambient pressure and measured using a digital bubble flow meter. Membrane selectivity was periodically checked by applying a pure He feed gas at 10 psig. For all membranes discussed no leaks were detected, and thus the selectivity was found to be infinite. 


\subsection{Microscopy and compositional analysis}

All membranes were characterized before and after permeation testing using a JEOL JSM-7000F field emission scanning electron microscopy (FESEM) to assess changes in surface morphology. Elemental composition was measured via EDAX electron dispersive X-ray spectroscopy (EDS). Compositions were measured at accelerating voltages of 10 and $15 \mathrm{kV}$, which have different penetrating depths and help to infer differences between the near surface and bulk compositions.

\section{Results}

\subsection{Permeability Measurements}

After heating to $500{ }^{\circ} \mathrm{C}$ in helium the membranes were exposed to pure $\mathrm{H}_{2}$ and the permeate flow rate was recorded as a function of time until its value dropped below the detectable threshold of $0.1 \mathrm{sccm}$. Fig. 1 plots the experimental permeability determined from these experiments versus time for each $\mathrm{Pd} / \mathrm{BCC}$ membrane as well as the theoretical permeabilities of each BCC metal calculated by Steward [7]. The experimentally determined permeability for a cold rolled 25 micron thick $\mathrm{Pd}_{75} \mathrm{Ag}_{25}$ alloy foil at $500{ }^{\circ} \mathrm{C}$ is also included for comparison. The experimentally achieved $\mathrm{PdAg}$ permeability is consistent with previous literature and validates our experimental design [27]. All three $\mathrm{Pd} / \mathrm{BCC}$ composites displayed qualitatively similar behavior. Initially the flux increased and shortly after the start of testing $(<2$ hours) the permeability of all three membranes approached their theoretical limit and then began to decline at varying rates. The experimentally achieved values for both permeability and permeance are summarized in Table 1. All samples closely approached the theoretical limit $(89-99 \%)$.

The $\mathrm{H}_{2}$ permeabilities for $\mathrm{Pd} /$ group $\mathrm{V}$ transition metal composite membranes at $500{ }^{\circ} \mathrm{C}$ are significantly greater than those previously reported. Literature $\mathrm{H}_{2}$ permeability values for $\mathrm{Pd} / \mathrm{V}$ 
membranes range from $11 \%$ [9] to $41 \%$ [28] of theoretical expectations at temperatures in the range of $350-500{ }^{\circ} \mathrm{C}$. For $\mathrm{Pd} / \mathrm{Nb}$ membranes the reported $\mathrm{H}_{2}$ permeabilities in the same temperature range is $30 \%$ [23] to $70 \%$ [9] of theoretical for flat substrates and $74 \%$ of theoretical for tubular substrates [10]. Likewise, Pd/Ta membranes have been shown to have permeabilities $4 \%$ [16] to $66 \%$ [11] of theoretical for flat substrates, and $62 \%$ of theoretical for tubular substrates [10]. There are a couple reasons for the improved values obtained in this study. First, the presence of BCC-oxides can provide significant hydrogen transport resistance as well, but our method of in situ high vacuum oxide removal and subsequent Pd deposition avoids this problem. Second, the thickness of the Pd catalyst layers is quite thin $(100 \mathrm{~nm})$, which provides sufficient catalytic ability to dissociate $\mathrm{H}_{2}$ while not introducing a significant barrier to atomic hydrogen transport. 


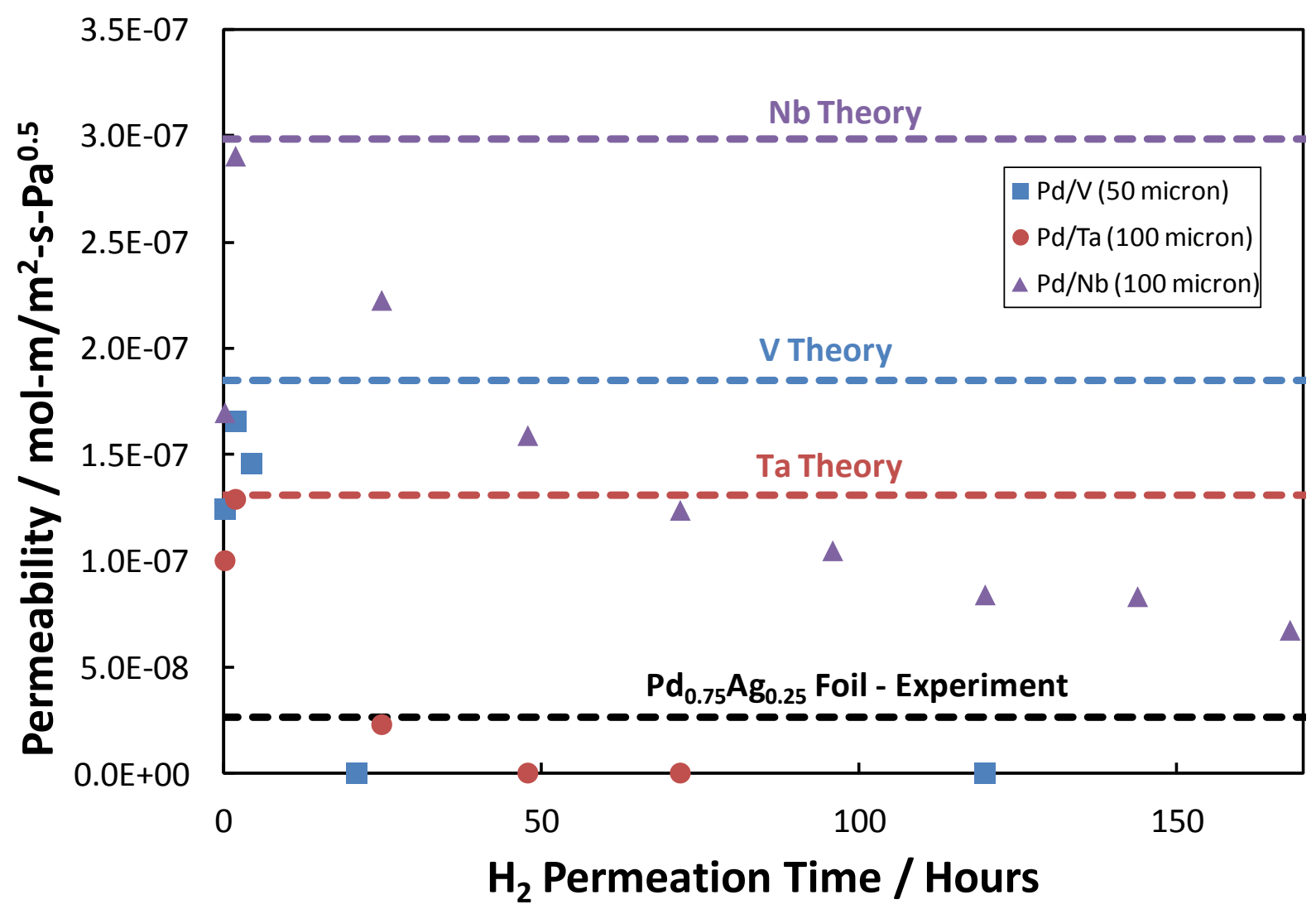

Figure 1. Experimental permeability vs. time at $500^{\circ} \mathrm{C}$ for $\mathrm{Pd} / \mathrm{BCC}$ membranes compared with theoretical permeabilities of each BCC metal and experimentally achieved permeability for a 25 micron $\mathrm{Pd}_{75} \mathrm{Ag}_{25}$ cold rolled foil.

The maximum $\mathrm{H}_{2}$ permeance values for each of the $\mathrm{Pd} / \mathrm{BCC}$ membranes and for the $\mathrm{PdAg}$ foil are also listed in Table 1. Impressively, each of the Pd/BCC permeance values exceeds that of the $25 \mu \mathrm{m}$ PdAg foil, despite the fact that the $\mathrm{V}$ foil is two times as thick, and the $\mathrm{Ta}$ and $\mathrm{Nb}$ foils are four times as thick as the PdAg alloy. The thickness of the PdAg membrane would need to be reduced to 8-9 $\mu \mathrm{m}$ in order to match the impressive permeance achieved in both the $\mathrm{Pd} / \mathrm{Nb}$ and $\mathrm{Pd} / \mathrm{V}$ systems. For PdAg films of these thicknesses it becomes cost effective to use an electroless plating method on a ceramic support rather than a cold rolled foil. This type of fabrication method, especially at thicknesses below $10 \mu \mathrm{m}$, is prone to defects and pinhole leaks 
that decrease $\mathrm{H}_{2}$ selectivity. Because of this it would be difficult to obtain the combination of high permeance and infinite selectivity observed with the $\mathrm{Pd} / \mathrm{BCC}$ foils with a PdAg membrane.

Table 1 - Comparison of theoretical $[7,27]$ and experimentally achieved $\mathrm{H}_{2}$ permeability at $500^{\circ} \mathrm{C}$ for the membranes evaluated in this work. . Additionally, maximum experimentally achieved $\mathrm{H}_{2}$ permeance of $\mathrm{Pd} / \mathrm{BCC}$ composite membranes at $500{ }^{\circ} \mathrm{C}$.

\begin{tabular}{|c|c|c|c|}
\hline $\begin{array}{c}\text { Pd/BCC composite } \\
\text { membrane }\end{array}$ & $\begin{array}{c}\text { Achieved } \\
\text { permeability } \\
\left(\mathbf{m o l}-\mathbf{m} / \mathbf{m}^{\mathbf{2}} \text {-s- }\right. \\
\left.\mathbf{P a}^{\mathbf{0 . 5}}\right)\end{array}$ & $\begin{array}{c}\text { Percent of } \\
\text { theoretical } \\
\text { permeability }\end{array}$ & $\begin{array}{c}\mathbf{P d} / \mathbf{B C C} \\
\text { maximum } \\
\text { permeance } \\
\left(\mathbf{m o l} / \mathbf{m}^{\mathbf{2}} \text {-s-Pa }\right.\end{array}$ \\
\hline $\mathbf{P d} / \mathbf{V} \mathbf{( 5 0} \boldsymbol{\mu m} \mathbf{~ V )}$ & $1.65 \times 10^{-7}$ & $89.4 \%$ & $3.31 \times 10^{-3}$ \\
\hline $\mathbf{P d} / \mathbf{N b}(\mathbf{1 0 0} \boldsymbol{\mu m} \mathbf{~ N b )}$ & $2.90 \times 10^{-7}$ & $97.1 \%$ & $2.90 \times 10^{-3}$ \\
\hline $\mathbf{P d} / \mathbf{T a}(\mathbf{1 0 0} \boldsymbol{\mu m} \mathbf{~ T a})$ & $1.29 \times 10^{-7}$ & $98.5 \%$ & $1.29 \times 10^{-3}$ \\
\hline $\left.\mathbf{P d}_{\mathbf{7 5}} \mathbf{A g}_{\mathbf{2 5}} \mathbf{( 2 5} \boldsymbol{\mu m}\right)$ & $2.69 \times 10^{-8}$ & $97.5 \%$ & $1.10 \times 10^{-3}$ \\
\hline
\end{tabular}

As shown in Fig. 1 the three BCC metals exhibited very different stability behavior, reflecting their unique failure mechanisms. $\mathrm{Pd} / \mathrm{V}$ showed the most rapid decline in performance with undetectable $\mathrm{H}_{2}$ flow being recorded after only 20 hours. $\mathrm{Pd} / \mathrm{Ta}$ exhibited somewhat improved stability, displaying permeability to around 48 hours. $\mathrm{Pd} / \mathrm{Nb}$ had a surprising result in that, while there was a significant decline from its maximum value, the $\mathrm{Pd} / \mathrm{Nb}$ composite membrane still exhibited relatively high permeability throughout the 168 hours of $\mathrm{H}_{2}$ permeation testing at $500^{\circ} \mathrm{C}$. Next the mechanism of failure for each membrane was investigated via FESEM imaging and EDS compositional analysis before and after permeation testing.

\subsection{Stability of the Pd/V membranes}

Fig. 2 compares the surface of $\mathrm{Pd} / \mathrm{V}$ before and after $\mathrm{H}_{2}$ permeation testing. It can be seen that the membrane surface before and after testing is largely unchanged and has the appearance of a cold rolled foil. In addition, no physical deformation of the membrane was observed after testing. Fig. 3 provides a summary of the composition data obtained from $\mathrm{Pd} / \mathrm{V}$ membranes 
before and after $\mathrm{H}_{2}$ permeation testing. EDS spectra were taken at 10 and $15 \mathrm{kV}$ to examine the composition at different electron penetration depths. This is illustrated by measurements taken from a membrane prior to testing. The Pd: $\mathrm{V}$ ratio measured before testing was 2.05 and 0.52 for accelerating voltages of 10 and $15 \mathrm{kV}$, respectively. This suggests that at $10 \mathrm{kV}$ the electron beam samples the $100 \mathrm{~nm} \mathrm{Pd}$ and approximately $175 \mathrm{~nm}$ of the underlying $\mathrm{V}$ foil. At $15 \mathrm{kV}$ the sample is measured $\sim 4$ times deeper into $\mathrm{V}$, or approximately $700 \mathrm{~nm}$ into the $\mathrm{V}$ foil. After $\mathrm{H}_{2}$ permeation testing the $\mathrm{Pd}: \mathrm{V}$ ratio at $10 \mathrm{kV}$ drops substantially to $\sim 0.8$, with very similar values observed on both the feed and permeate sides. In contrast, the measured $\mathrm{Pd}: \mathrm{V}$ ratio at $15 \mathrm{kV}$ was


Figure 2. FESEM images of Pd/V feed side (a) before and (b) after 24 hours of $\mathrm{H}_{2}$ permeation testing at $500^{\circ} \mathrm{C}$. Feed and permeate sides have similar appearance. 


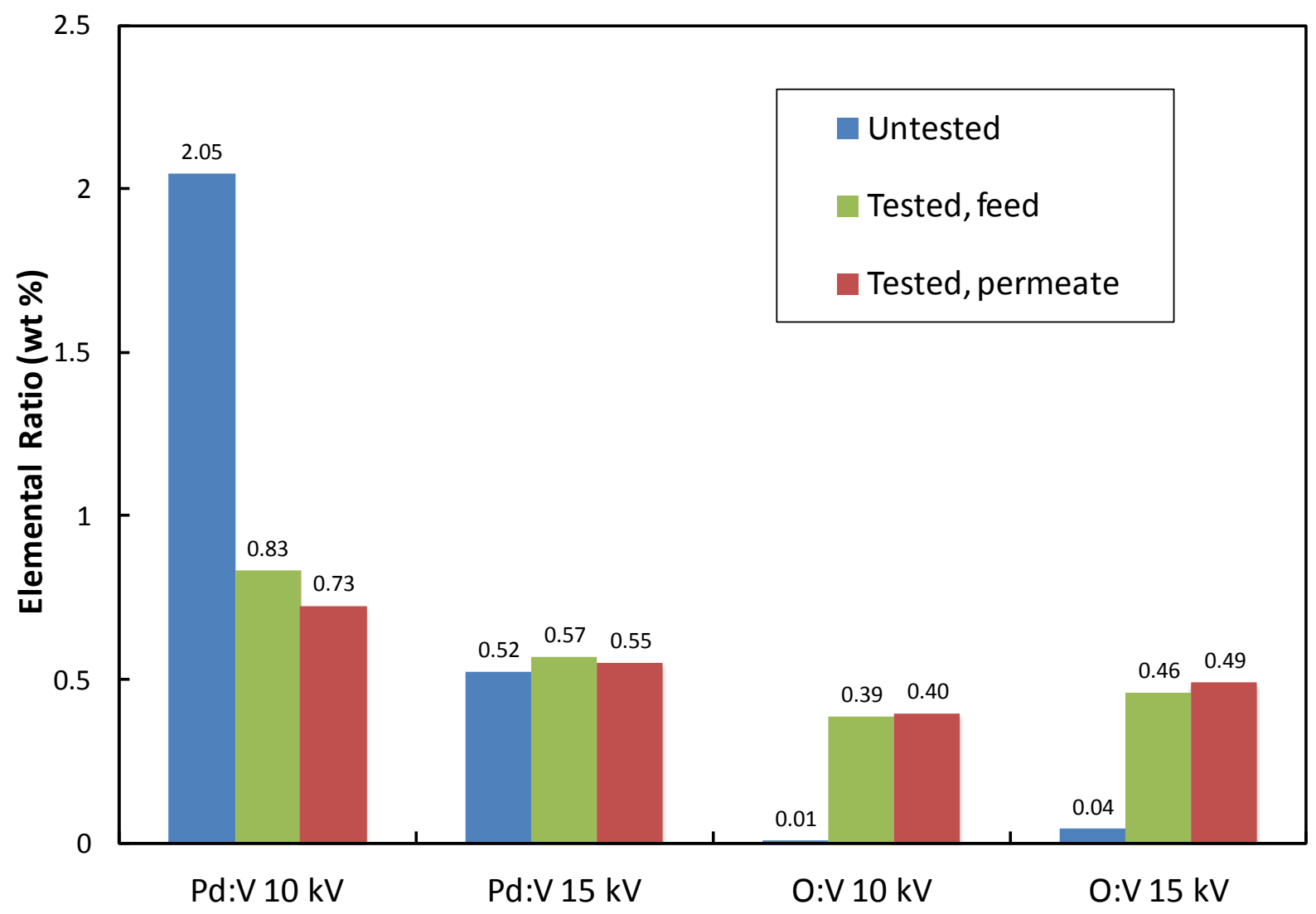

Figure 3. Summary of Pd:V and 0:V elemental ratios ( weight \%) as determined by EDS at two accelerating voltages from a $\mathrm{Pd} / \mathrm{V}$ membrane before and after $\mathrm{H}_{2}$ permeation testing at $500^{\circ} \mathrm{C}$ for 24 hours.

essentially unchanged after testing. This indicates that Pd has not been lost from the sample, but that it has migrated into the bulk $\mathrm{V}$ foil via diffusion and/or alloying. This finding is consistent with previous reports of Pd-V interdiffusion. Edlund et al.[21] observed intermetallic diffusion using cross sectional microscopy analysis of a $25 \mu \mathrm{m}$ Pd coated $25 \mu \mathrm{m} \mathrm{V}$ composite membrane. In that work the $\mathrm{H}_{2}$ flux was observed to approach zero within 25 hours of testing, very similar to what was observed here despite using much thicker Pd layers. This work also indicated that $\mathrm{V}$ diffuses more readily into Pd than the reverse process. The estimated diffusion coefficient $(D)$ for V into Pd was $8 \times 10^{-11} \mathrm{~cm}^{2} / \mathrm{s}$ as compared to $D=1 \times 10^{-11} \mathrm{~cm}^{2} / \mathrm{s}$ for Pd diffusing into V. Additionally, Edlund and coworkers [21] hypothesized that the alloying of Pd-V could make 
complexes that reduce the permeability of hydrogen. Buxbaum et al. also reported interdiffusion as the primary cause of $\mathrm{Pd} / \mathrm{V}$ membrane degradation using $2 \mathrm{~mm}$ thick $\mathrm{V}$ disks electrolessly coated with 1-2 $\mu \mathrm{m}$ of Pd [9].

The other significant change observed after permeation was the appearance of significant quantities of oxygen. Two potential contamination sources were considered. Oxygen could originate due to impurities in the foil or from the industrial grade $\mathrm{H}_{2}$ that was used for permeation testing. We have accumulated a good deal of experience with $\mathrm{V}$ foils through our work developing composite membranes employing $\mathrm{Mo}_{2} \mathrm{C}$ as the catalyst layer [12,13]. Though high permeability has been achieved, at times results have been inconsistent and the quality of the foils has been questioned. Moreover, as-received foils with nominally identical purity can vary substantially in visual appearance from shiny to dull grey, and it is suspected that oxygen impurities are responsible for such variability. Table 2 shows the melting points of $\mathrm{V}, \mathrm{Nb}, \mathrm{Ta}$ and their associated oxides [29]. These BCC metals are somewhat unique in that their oxides melt at much lower temperatures. In particular, it is noted that the melting point of $\mathrm{V}_{2} \mathrm{O}_{5}$ is very low, and if present, it is expected to be very mobile at the membrane testing temperature of 500 ${ }^{\circ} \mathrm{C}$. Further evidence suggesting that oxygen originates in the foils is provided by EDS analysis. Though the differences are not great, in every sample tested the $\mathrm{O}: \mathrm{V}$ ratio was greater when measured at $15 \mathrm{kV}$ as opposed to $10 \mathrm{kV}$. If oxygen was predominantly supplied from gas-phase impurities one would expect its concentration to be higher in the near surface region. The presence of oxygen in the foil may also explain why the maximum permeability obtained with $\mathrm{V}$ relative to its theoretical potential was lower than the Ta and Nb-based composites ( $\sim 89$ vs. 98\%). However, gas-phase impurities cannot be completely ruled out as a source of oxygen. 
As discussed below, significant oxygen was also detected on $\mathrm{Nb}$-based membranes after $\mathrm{H}_{2}$ permeation testing, but in this case the oxygen was concentrated at the surface.

Table 2. Melting points of the BCC elements and their associate oxides [29].

\begin{tabular}{|c|c|c|c|c|c|c|}
\hline Material & $\mathrm{V}$ & $\mathrm{V}_{2} \mathrm{O}_{5}$ & $\mathrm{Nb}$ & $\mathrm{Nb}_{2} \mathrm{O}_{5}$ & $\mathrm{Ta}$ & $\mathrm{Ta}_{2} \mathrm{O}_{5}$ \\
\hline $\begin{array}{c}\text { Melting } \\
\text { Point }\left({ }^{\circ} \mathbf{C}\right)\end{array}$ & 1917 & 690 & 2468 & 1520 & 2946 & 1872 \\
\hline
\end{tabular}

\subsection{Stability of the Pd/Ta membranes}

Fig. 4 compares the Pd/Ta surface before and after testing. The appearance of the untested $\mathrm{Pd} /$ Ta surface is that of a cold rolled foil, as expected (Fig. 4a). After 72 hours of $\mathrm{H}_{2}$ permeation testing the membrane was removed from the system and found to be intact, but that the membrane was bowed towards the feed side, as shown schematically in Fig. 4b. This is interesting in that the Ta deformed against the imposed pressure gradient. Hydrogen absorption in metals causes volume expansion of the metal host lattice. In our permeation setup where the thin films are clamped it creates a biaxial stress state: lateral film expansion is suppressed, creating large compressive in-plane stresses that can increase by several GPa with increasing hydrogen content [30]. This bowing influenced the morphology of the $\mathrm{Pd} / \mathrm{Ta}$ membrane after permeation testing, as observed in micrographs of the permeate and feed side shown in Figs. 4c and $\mathbf{4 d}$, respectively. In both cases the surface is significantly rougher after testing, and there are areas of partial Pd delamination, as confirmed by EDS, although Pd still covers most of the membrane surface. The degree of roughening/delamination is more pronounced on the feed side of the $\mathrm{Pd} / \mathrm{Ta}$ membrane. This asymmetry is consistent with the observed deformation described above, which places the feed surface under tensile stress and the permeate surface under 
compressive stress. These results suggest that the former is more detrimental to the integrity of the Pd film.

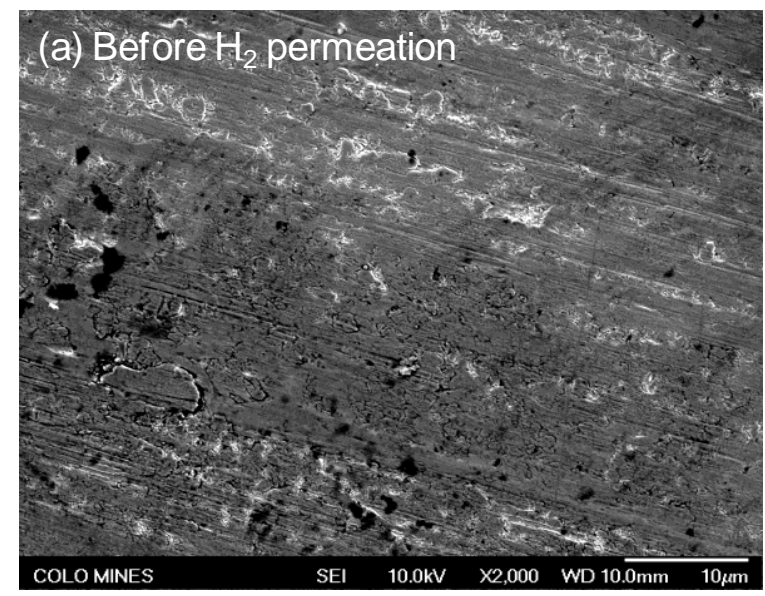

(b) Schematic of membrane deformation
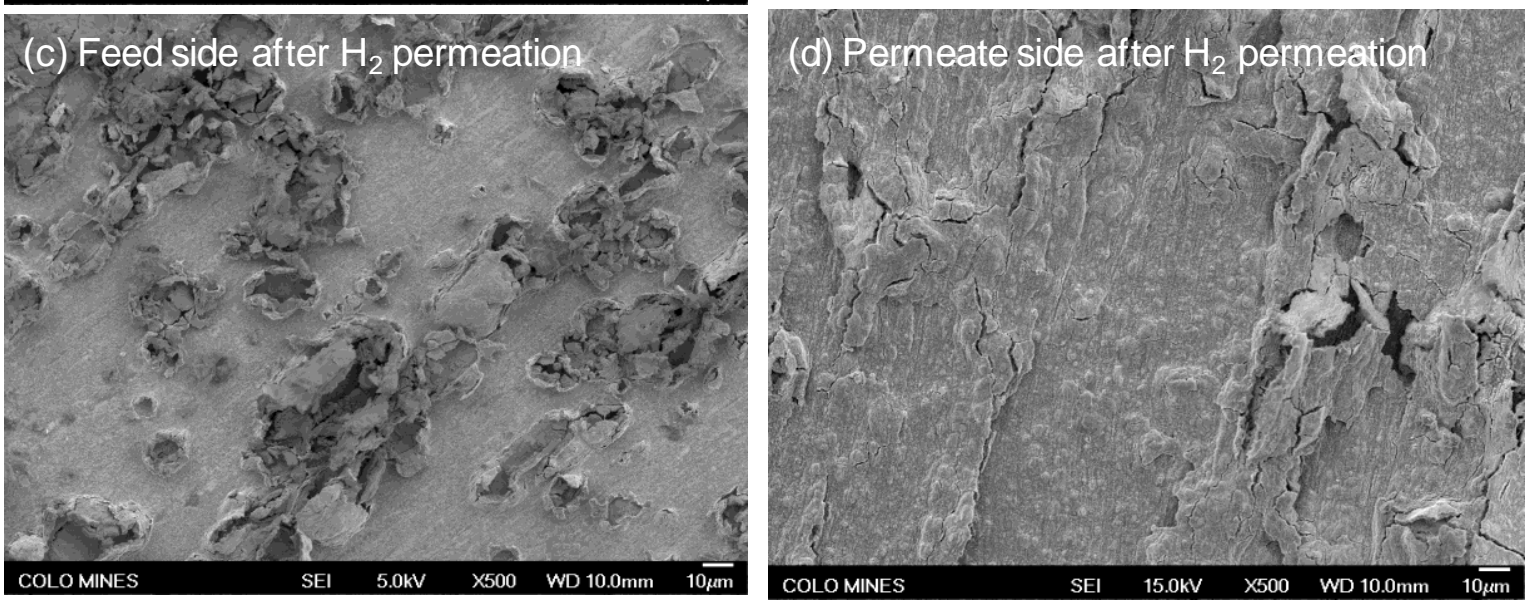

Figure 4. FESEM images of the Pd/Ta membrane surface (a) before testing; (b) a schematic diagram of deformation observed after testing; (c) the morphology of feed side after $\mathrm{H}_{2}$ permeation; (d) the morphology of permeate side after $\mathrm{H}_{2}$ permeation.

The EDS determined ratios of $\mathrm{Pd}: \mathrm{Ta}$ and $\mathrm{O}: \mathrm{Ta}$ before and after testing are summarized in

Fig. 5. The data presented are from the feed side, but nominally identical results were obtained from the permeate side. This would suggest that the morphological differences discussed above are due to mechanical stress and not chemical in origin. In stark contrast to $\mathrm{V}$, negligible oxygen is observed in these membranes, indicating that little oxide diffusion or gettering occurs in the $\mathrm{Pd} / \mathrm{Ta}$ system. However, like $\mathrm{Pd} / \mathrm{V}$, the issue of $\mathrm{Pd}$ interdiffusion and alloying remains. The Pd:Ta ratio in the near surface region $(10 \mathrm{kV})$ decreased significantly after testing, while at 15 
$\mathrm{kV}$ the $\mathrm{Pd}$ :Ta ratio remained relatively constant, indicating that $\mathrm{Pd}$ interdiffusion and alloying is also significant in this material system.



Figure 5. Summary of Pd:Ta and 0:Ta elemental ratios ( weight \%) as determined by EDS at two accelerating voltages from a Pd/Ta membrane before and after $\mathrm{H}_{2}$ permeation testing at $500^{\circ} \mathrm{C}$ for 72 hours. The data presented are from the feed side, but nominally identical results were obtained from the permeate side.

The results described above are consistent with most previous accounts of Ta behavior in literature. Peachey et al. observed Pd-Ta interdiffusion via Rutherford backscattering spectroscopy when testing at temperatures between 300 and $400^{\circ} \mathrm{C}$ using $12 \mu \mathrm{m}$ Ta foils sputter coated with $1 \mu \mathrm{m}$ of Pd on each side [16]. Peachey and coworkers continued to see permeation over the course of two days, but noted that longer term use would become problematic due to the rate of Pd-Ta interdiffusion. Additionally, Buxbaum et al. reported interdiffusion in $\mathrm{Pd} / \mathrm{Ta}$ 
membrane systems [9]. In this case Buxbaum used $2 \mathrm{~mm}$ thick Ta planar disks with electrolessly deposited Pd films of 1 to $2 \mu \mathrm{m}$ thickness. They found that these membranes did not degrade significantly over the course of 67 hours of testing at temperatures in the range of $350-415^{\circ} \mathrm{C}$ [9]. These authors suggested that Ta was the most promising of the three group $\mathrm{V}$ transition metals because of its relatively low hydrogen solubility, which lower the risk of hydrogen embrittlement. Unlike the results of Peachey and Buxbaum, Rothenberger et al. reported that the primary mechanism for $\mathrm{Pd}$ loss in $\mathrm{Pd} / \mathrm{Ta}$ membranes over 49 hours at $500^{\circ} \mathrm{C}$ was delamination of the Pd catalyst layer and not interdiffusion [11]. This was found using $1 \mathrm{~mm}$ Ta disks that had been sputter cleaned and coated with $1.2 \mu \mathrm{m}$ of Pd. Under the conditions examined here it appears that both mechanisms contribute to loss of permeability.

It should be noted that of the three $\mathrm{BCC}$ metals $\mathrm{Pd} / \mathrm{Ta}$ seemed to be the most prone to breaking upon heat up and pressure changes. Ta foils of thickness 50 microns or less frequently during the initial heat up to $500{ }^{\circ} \mathrm{C}$ under UHP He. Furthermore, despite its lower solubility it was observed that $50 \mu \mathrm{m}$ Ta foils that survived heating were highly prone to $\mathrm{H}_{2}$ embrittlement, and would turn into a dusty white powder when exposed to hydrogen pressures above $20 \mathrm{psig}$. The use of thicker $100 \mu \mathrm{m}$ Ta foils resolved this issue for the conditions explored in this work.

\subsection{Stability of the Pd/Nb membranes}

Of the three $\mathrm{Pd} / \mathrm{BCC}$ composites $\mathrm{Pd} / \mathrm{Nb}$ showed the most promising result in that after an initial decrease in permeability, failure did not occur, and permeation began to stabilize with significant $\mathrm{H}_{2}$ flowrates observed throughout the duration of testing (1 week). As expected the changes in morphology and composition after testing were significantly distinct from either $\mathrm{V}$ or $\mathrm{Ta}$. The FESEM image shown in Fig. 6a indicates that like the other Pd/BCC membranes Pd/Nb has the appearance of a smooth, cold rolled metal foil prior to permeation testing. In contrast to Ta, it 


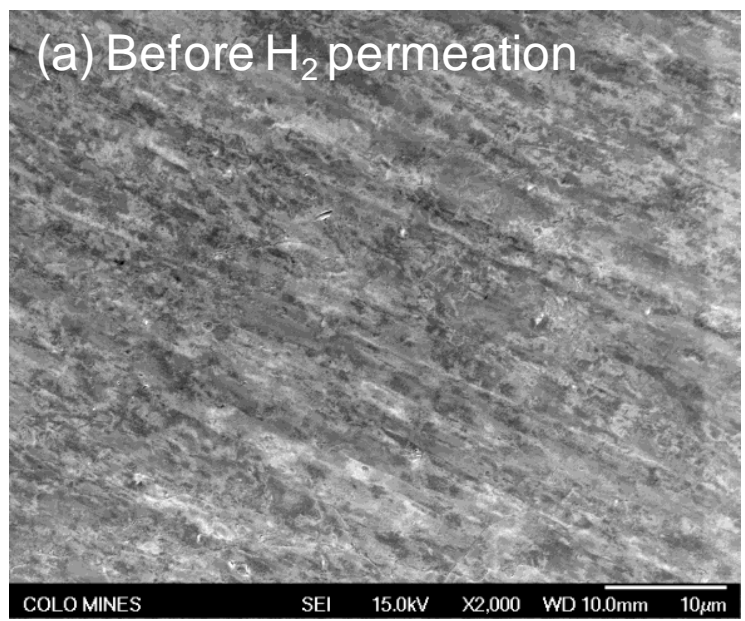

\section{(b) Schematic of membrane} deformation


Figure 6. FESEM images of the Pd/Nb membrane surface (a) before testing; (b) a schematic diagram of deformation observed after testing; (c) the morphology of feed side after $\mathrm{H}_{2}$ permeation; (d) the morphology of permeate side after $\mathrm{H}_{2}$ permeation.

was observed that the $\mathrm{Pd} / \mathrm{Nb}$ membrane deformed towards the permeate side during testing as

illustrated schematically in Fig. 6b. Significant Pd delamination was observed after permeation testing as shown in Figs. $\mathbf{6 c}$ and $\mathbf{6 d}$ for the feed and permeate surfaces, respectively. On both sides there were large areas of $\mathrm{Nb}$ exposed that were originally covered by a uniform layer of $\mathrm{Pd}$. This creates surface roughness that is visually apparent when the sample is removed from the testing apparatus. Consistent with the Ta results, the surface under tensile stress (permeate side) experienced more delamination than the surface experiencing compressive stress (feed side). 
Though difficult to quantify precisely, it was clear that less than half of the Pd remained on the permeate side while the majority of the surface of the feed side remained covered by Pd. Such buckling behavior has been recently reported for niobium hydrogen films, and this phenomenon has been associated with the formation of the hydride phase [31].

Similar delamination behavior was reported in previous experiments of Pd-coated $\mathrm{Nb}$ membranes. Busnyuk et al. observed that Pd sputtered films of thickness 25, 250 and $1000 \mathrm{~nm}$ on $100 \mu \mathrm{m} \mathrm{Nb}$ foil will delaminate, but are unlikely to interdiffuse at $600^{\circ} \mathrm{C}$ [22]. These results are in partial contrast to Sasaki et al., who reported both cracking and Pd-Nb interdiffusion in a $200 \mathrm{~nm}$ Pd sputter coated $0.5 \mathrm{~mm} 95 \mathrm{~mol} \% \mathrm{Nb}-5 \mathrm{~mol} \% \mathrm{~W}$ foil [23]. Sasaki et al. assessed this via heating $\mathrm{Pd}$ coated $\mathrm{Nb}$ in an inert environment to $500^{\circ} \mathrm{C}$ while in situ monitoring Pd deformation via TEM and Pd-Nb interdiffusion via cross sectional EDS. Moreover, Sasaki and coworkers saw hydrogen permeability initially start at around $66 \%$ of theoretical pure $\mathrm{Nb}$, but fall to nearly zero within one day. Alimova et al. also observed $\mathrm{Pd}-\mathrm{Nb}$ interdiffusion, but only at $600^{\circ} \mathrm{C}$, whereas at $500^{\circ} \mathrm{C}$ no interdiffusion was observed [24]. This was found using a membrane consisting of $100 \mu \mathrm{m} \mathrm{Nb}$ foil sputter coated with $2 \mu \mathrm{m} \mathrm{Pd}$.

The compositional results for $\mathrm{Pd} / \mathrm{Nb}$ before and after testing are summarized in Figure 7. In this case scans were taken feed side, where it was easier to obtain data from regions with and without Pd present. The first observation is that in the Pd-coated regions the $\mathrm{Pd}: \mathrm{Nb}$ ratio is essentially unchanged before and after $\mathrm{H}_{2}$ permeation testing at both the 10 and $15 \mathrm{kV}$ accelerating voltages. This indicates that $\mathrm{Pd}$ alloying or diffusion into $\mathrm{Nb}$ is not occurring over the time scales tested, which is consistent with previous literature [22,24]. As expected no Pd is detected in regions where delamination occurred. This suggests that the observed decline in 
permeability is due to the reduced surface area available for catalytic dissociation/ recombination of $\mathrm{H}_{2}$.

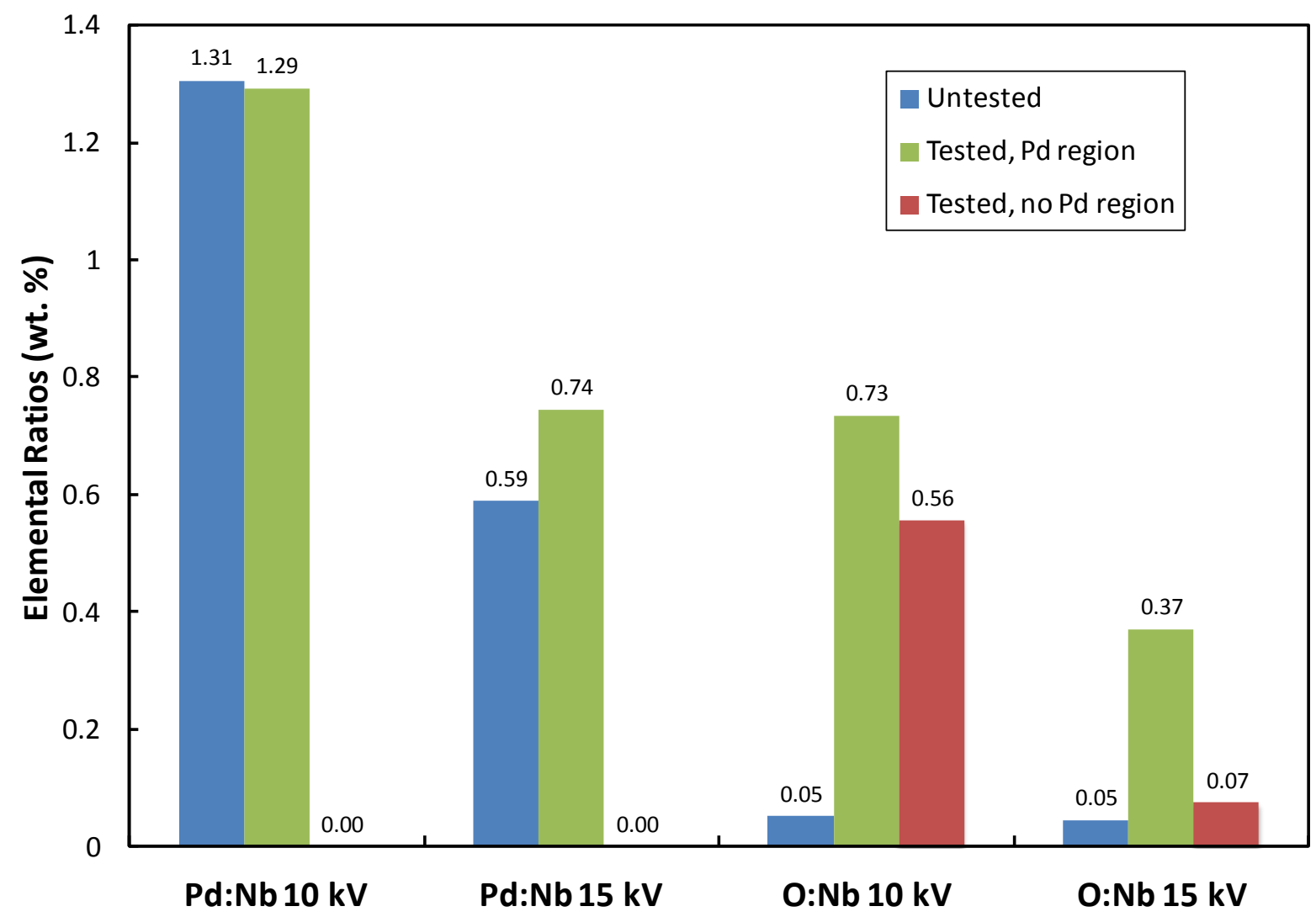

Figure 7. Summary of Pd:Nb and 0:Nb elemental ratios (wt. \%) determined by EDS for a Pd/Nb membrane before and after $\mathrm{H}_{2}$ permeation at $500^{\circ} \mathrm{C}$ for 168 hours. Data after permeation testing was obtained from regions with and without Pd present (Fig. 6).

The second interesting feature of $\mathrm{Pd} / \mathrm{Nb}$ was that significant $\mathrm{O}$ accumulation was detected after permeation testing. Moreover Fig. 7 shows that the measured O:Nb ratios are significantly greater at lower accelerating voltages, indicating that the oxygen content is localized on the surface of the membrane. This is in contrast to V, where the opposite behavior was observed, suggesting that in the $\mathrm{Nb}$ case $\mathrm{O}$ is due to impurities in the feed stream. It is also observed that 
the oxygen content is greater in regions where Pd is present, further supporting the idea that oxygen originates from impurities in the gas-phase, and that the mechanism for introduction is catalytic dissociation. This is consistent with gravimetric measurements of a $\mathrm{Pd} / \mathrm{Nb}$ membranes at elevated temperature in an oxygen environment, which showed that thin Pd films enhanced the rate of oxygen gettering [22].

\section{Discussion}

The results presented here combined with the previous literature provide a more complete understanding of the behavior of $\mathrm{Pd} / \mathrm{BCC}$ metal membranes. It is apparent that there is no one $\mathrm{Pd} / \mathrm{BCC}$ membrane system that is ideal for $\mathrm{H}_{2}$ separations, but rather each individual $\mathrm{Pd} / \mathrm{BCC}$ system has strengths and weaknesses that may be exploited dependent upon the particular application. The $\mathrm{Pd} / \mathrm{V}$ system displayed the most impressive mechanical properties of the three $\mathrm{Pd} / \mathrm{BCC}$ systems in that there were no difficulties experienced in heating up and cooling down a $50 \mu \mathrm{m}$ foil, and that this foil could withstand pressure gradients of over 100 psi without any evidence of deformation. The use of thinner foils allowed for $\mathrm{Pd} / \mathrm{V}$ to have the highest permeance of the three $\mathrm{Pd} / \mathrm{BCC}$ membranes, achieving a maximum of $3.31 \times 10^{-3} \mathrm{~mol} / \mathrm{m}^{2}-\mathrm{s}-\mathrm{Pa}^{0.5}$. The drawback of course is that $\mathrm{Pd} / \mathrm{V}$ was the least stable chemically. Vanadium was prone to oxidation, likely due to impurities in the foil, as well as Pd-V interdiffusion. These issues would need to be resolved in order to move forward to practical applications. Insertion of a diffusion barrier between the Pd and V foil is a proven strategy to prevent alloy formation [21], but this typically involves a tradeoff between reduced permeability and improved stability. The issue of oxidation susceptibility is an intrinsic issue that may require improved control during the production of $\mathrm{V}$ foils. 
The advantage of $\mathrm{Ta}$ is that it appears exceptionally resilient to oxidation, which may prove advantageous for application in an oxidizing environment such as purification of a water gas shift stream. However, like the Pd/V system it was also prone to interdiffusion and alloying, suggesting the need for a diffusion barrier for application at elevated temperature. Pd/Ta also showed issues with delamination; however, thicker films of Pd may mitigate this problem. Rothenberger et al. showed that electroless Pd coatings of $1 \mu \mathrm{m}$ could withstand high temperatures of up to $900^{\circ} \mathrm{C}$ without delamination or surface fouling, however this resulted in a significant decrease in permeability to around 7\% of theoretical [11]. Additionally, $\mathrm{Pd} / \mathrm{Ta}$ was observed to have the poorest mechanical properties of the group $\mathrm{V}$ transition metals, easily prone to breakage during heat-up or due to hydrogen embrittlement.

Of the composites examined in this work the $\mathrm{Pd} / \mathrm{Nb}$ system was perhaps the most promising. Not only did it achieve a permeability of $2.9 \times 10^{-7} \mathrm{~mol}-\mathrm{m} / \mathrm{m}^{2}-\mathrm{s}-\mathrm{Pa}^{0.5}$ and a permeance of $2.9 \times 10^{-3}$ $\mathrm{mol} / \mathrm{m}^{2}$-s-Pa ${ }^{0.5}$ for a $100 \mu \mathrm{m}$ foil, but it also showed no signs of Pd-Nb interdiffusion and retained relatively high permeability was observed over the course of 168 hours. The primary loss mechanism appeared to be delamination of the Pd due to mechanical stress induced by deformation. In principle this issue may be resolved through the use of mechanical support or alternative geometries such as cylinders. Oxygen was observed to accumulate on the Pd surface, presumably from gas-phase impurities, which may be problematic in oxidizing environments such as steam reforming. However, further testing needs to be conducted to better understand the impact of impurities on permeability. Nevertheless for this reason a $\mathrm{Pd} / \mathrm{Nb}$ system may be more applicable for producing high purity, high throughput $\mathrm{H}_{2}$ rather than membrane reforming. With an infinite selectivity and high permeance, the $\mathrm{Pd} / \mathrm{Nb}$ system could work very well creating the ultra high purity hydrogen required in a variety of applications such as semiconductor processing 
or polymer electrolyte membrane fuel cells. Lastly, there is significant ongoing work to develop BCC-based alloys that display improved properties over the elemental metals discussed here $[14,32]$. It is suggested that experimental approach described here would be an effective tool to screen the potential of new alloys for use as $\mathrm{H}_{2}$ separation membranes.

\section{Conclusions}

Composite membranes consisting of $100 \mathrm{~nm}$ of Pd on both sides of dense BCC metal foils (V, $\mathrm{Ta}, \mathrm{Nb}$ ) were permeated with pure $\mathrm{H}_{2}$ gas at $500{ }^{\circ} \mathrm{C}$. These membranes displayed experimental permeability values which approached the theoretical limit calculated by Steward, with Pd/V, $\mathrm{Pd} / \mathrm{Nb}$, and $\mathrm{Pd} / \mathrm{Ta}$ achieving $89 \%, 98 \%$ and $99 \%$ of the theoretical permeability for the respective metals. V membranes failed rapidly due to a combination of $\mathrm{Pd}$ dissolution and oxidation as shown through microscopy and compositional analysis. It is suggested that oxygen impurities in the $\mathrm{V}$ foil migrate to the surface during permeation testing. Ta membranes displayed little evidence of oxidation but greater care was required to prevent membrane failure due to mechanical stress and/or $\mathrm{H}_{2}$ embrittlement. These membranes failed within 48 hours, which was attributed to dissolution of $\mathrm{Pd}$. $\mathrm{Pd} / \mathrm{Nb}$ membranes exhibited high $\mathrm{H}_{2}$ flux/permeability during 168 hours of $\mathrm{H}_{2}$ permeation testing. It was observed that $\mathrm{Pd}$ did not alloy with $\mathrm{Nb}$ but experienced partial delamination, which reduced flux through the loss of active area for $\mathrm{H}_{2}$ dissociation/recombination. An increase in surface oxide content was also observed after $\mathrm{H}_{2}$ permeation, suggesting gettering gas-phase impurities, and this may also have contributed to the decrease in permeability with time. The permeance of these membranes was shown to be up to $3 x$ greater than the industry standard 25 micron $\operatorname{Pd}_{75} \mathrm{Ag}_{25}$ alloy membrane despite their thicknesses of $50-100$ microns. Strategies are suggested that may assist the further 
development of these systems, such as the use of tubular supports to reduced catalyst delamination, and the use of diffusion barriers to reduce catalyst-BCC interdiffusion.

\section{Acknowledgements}

We would like to thank the Pall Corporation for finacial support through DOE Contract DEFE0001181. In addition, DAC received partial support through a seed grant from the NSF sponsored Renewable Energy Material Research Science and Engineering Center (REMRSEC, DMR-0820518).

\section{References}

[1] Armaroli N, Balzani V. The hydrogen issue. ChemSusChem 2011;4:21-36.

[2] Mueller-Langer F, Tzimas E, Kaltschmitt M, Peteves S. Techno-economic assessment of hydrogen production processes for the hydrogen economy for the short and medium term. Int. J. Hydrogen Energy 2007;32:3797-3810.

[3] Roy S, Cox BG, Adris AM, Pruden BB. Economics and simulation of fluidized bed membrane reforming. Int. J. Hydrogen Energy 1998;23:745-752.

[4] Paglieri S, Way JD. Innovations in palladium membrane research. Sep. Purif. Method. 2002;31:1-169.

[5] Yun S, Oyama ST. Correlations in palladium membranes for hydrogen separation: A review. J. Membr. Sci. 2011;375:28-45.

[6] Criscuoli A, Basile A, Drioli E, Loiacono O. An economic feasibility study for water gas shift membrane reactor. J. Membr. Sci. 2001;181:21-27.

[7] Steward SA. Review of hydrogen isotope permeability through materials; Lawrence Livermore National Laboratory Report UCRL-53441: Livermore, CA, 1983.

[8] Sherman R, Birnbaum HK. Hydrogen permeation and diffusion in niobium. Metall. Trans. A 1983;14:203-210.

[9] Buxbaum RE, Marker TL. Hydrogen transport through non-porous membranes of palladium-coated niobium, tantalum and vanadium. J. Memb. Sci. 1993;85:29-38.

[10] Buxbaum RE, Kinney AB. Hydrogen transport through tubular membranes of palladiumcoated tantalum and niobium. Ind. Eng. Chem. Res. 1996;35:530-537.

[11] Rothenberger KS, Howard BH, Killineyer RP, Cugini AV, Enick RM, Bustamante F, Ciocco MV, Morreale BD, Buxbaum RE. Evaluation of tantalum-based materials for hydrogen separation at elevated temperatures and pressures. J. Membr. Sci. 2003;218:1937. 
[12] Wolden CA, Adeyemo K, Vervuurt RHJ, Ostwal M, Way JD. Mechanistic studies of hydrogen transport through $\mathrm{Mo}_{2} / \mathrm{V}$ composite membranes. J. Membr. Sci. 2013;427:150154.

[13] Gade SK, Chmelka SJ, Parks S, Way JD, Wolden CA. Dense carbide/metal composite membranes for hydrogen separations without platinum group metals. Adv. Mater. 2011;23:3585-3589

[14] Dolan MD. Non-Pd BCC alloy membranes for industrial hydrogen separation. J. Membr. Sci. 2010;362:12-28.

[15] Jayaraman V, Lin YS, Pakala M, Lin RY. Fabrication of ultrathin metallic membranes on ceramic supports by sputter deposition. J. Membr. Sci. 1995;99:89-100.

[16] Peachey NM, Snow RC, Dye RC. Composite Pd/Ta metal membranes for hydrogen separation. J. Membr. Sci. 1996;111:123-133.

[17] Paglieri SN, Wermer JR, Buxbaum RE, Ciocco MV, Howard BH, Morreale BD. Development of membranes for hydrogen separation: Pd coated V-10Pd Energ. Mater. 2008;3:169-176.

[18] Nambu T, Shimizu K, Matsumoto Y, Rong R, Watanabe N, Yukawa H, Morinaga M, Yasuda I. Enhanced hydrogen embrittlement of Pd-coated niobium metal membrane detected by in situ small punch test under hydrogen permeation. J. Alloys Compounds 2007;446-447:588-592.

[19] Dolan MD, Song G, Liang D, Kellam ME, Chandra D, Lamb JH. Hydrogen transport through $\mathrm{V}_{85} \mathrm{Ni}_{10} \mathrm{M}_{5}$ alloy membranes. J. Membr. Sci. 2011;373:14-19.

[20] Lee Y-S, Ouyang C, Suh J-Y, Fleury E, Cho YW, Shim J-H. Role of alloying elements in vanadium-based binary alloy membranes for hydrogen separation. J. Membr. Sci. 2012;423-424:332-341.

[21] Edlund DJ, Mccarthy J. The relationship between intermetallic diffusion and flux decline in composite-metal membranes: Implications for achieving long membrane lifetime. J. Membr. Sci. 1995;107:147-153.

[22] Busnyuk AO, Notkin ME, Grigoriadi IP, Alimov VN, Lifshitz AI. Thermal degradation of a palladium coating on hydrogen-tight niobium membranes. Tech. Phys. 2010;55:117-124.

[23] Sasaki K, Hattori M, Tsuchimoto K, Yukawa H, Arai S, Tokunaga T, Murata Y, Yamamoto T. Microstructural analysis of thermal degradation of palladium-coated niobium membrane. J. Alloys Compounds 2013;573:192-197.

[24] Alimova VN, Hatano Y, Busnyuk AO, Livshits DA, Notkin ME, Livshits AI. Hydrogen permeation through the $\mathrm{Pd}-\mathrm{Nb}-\mathrm{Pd}$ composite membrane: Surface effects and thermal degradation. Int. J. Hydrogen Energy 2011;36:7737-7746.

[25] Hatano Y, Ishiyama K, Homma H, Watanabe K. Improvement of high temperature stability of $\mathrm{Pd}$ coating on $\mathrm{Nb}$ by intermediate layer comprising $\mathrm{NbC}$ and $\mathrm{Nb}_{2} \mathrm{C}$. J. Alloys Compounds 2007;446:539-542.

[26] Dolan MD, McLennan KG, Way JD. Diffusion of atomic hydrogen through V-Ni alloy membranes under nondilute conditions. J. Phys. Chem. C 2012;116:1512-1518.

[27] Holleck GL. Diffusion and solubility of hydrogen in palladium and palladium--silver alloys. J. Phys. Chem. 1970;74:503-511.

[28] Ozaki T, Zhang Y, Komaki M, Nishimura C. Preparation of palladium-coated V and V$15 \mathrm{Ni}$ membranes for hydrogen purification by electroless plating technique. Int. J. Hydrogen Energy 2003;28:297-302. 
[29] The merck index, an encyclopedia of chemicals, drugs, and biologicals; 11 ed.; Merck \& Co., Inc.,, 1989.

[30] Pundt A. Hydrogen in nano-sized metals. Advanced Engineering Materials 2004;6:11-21.

[31] Wagner S, Moser M, Greubel C, Peeper K, Reichart P, Pundt A, Dollinger G. Hydrogen microscopy - distribution of hydrogen in buckled niobium hydrogen thin films. Int. J. Hydrogen Energy 2013;38:13822-13830.

[32] Zhang GX, Yukawa H, Nambu T, Matsumoto Y, Morinaga M. Alloying effects of ru and w on hydrogen diffusivity during hydrogen permeation through $\mathrm{Nb}$-based hydrogen permeable membranes. Int. J. Hydrogen Energy 2010;35:1245-1249. 
Graphical Abstract

Graphical Abstract






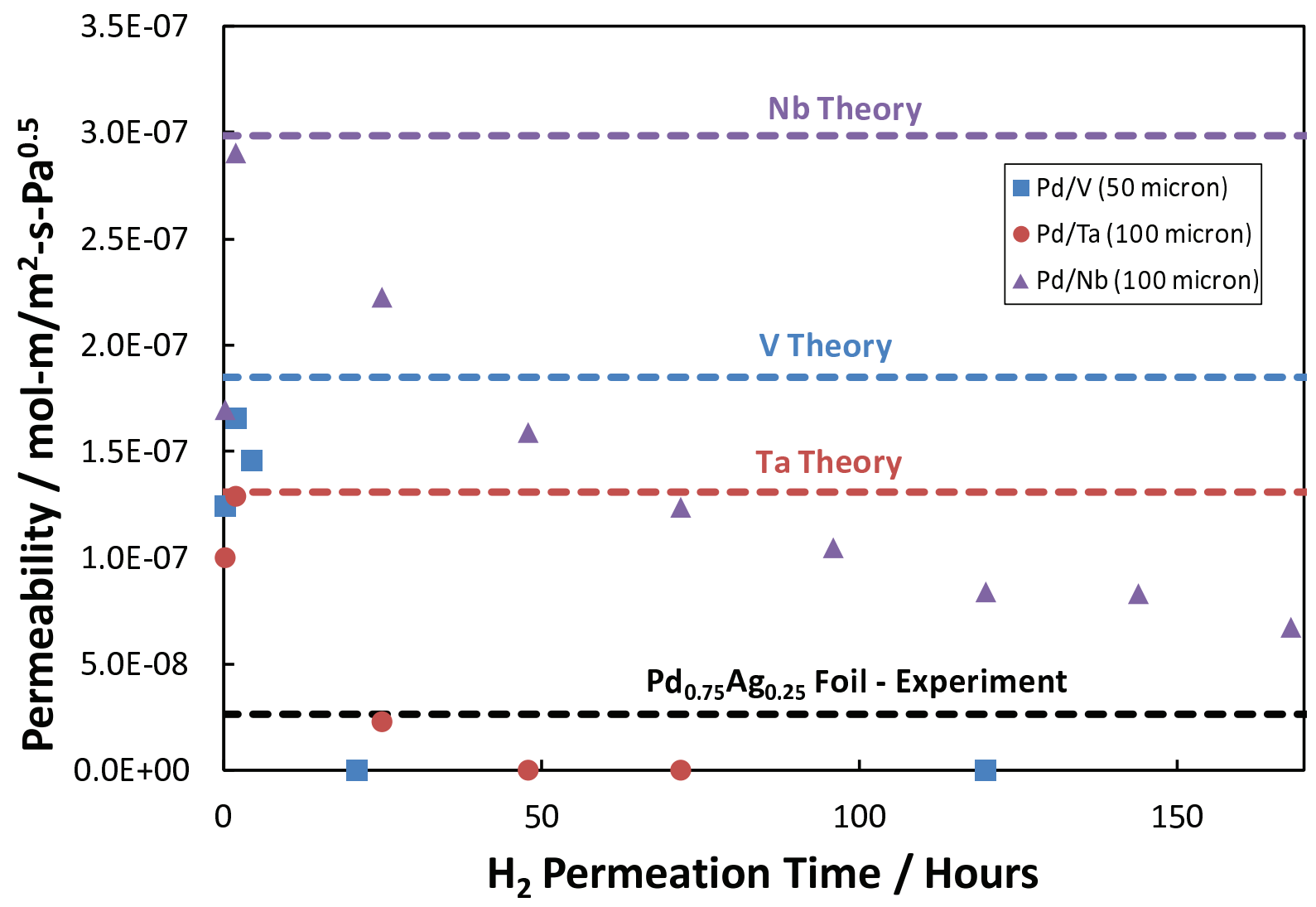


Figure 3

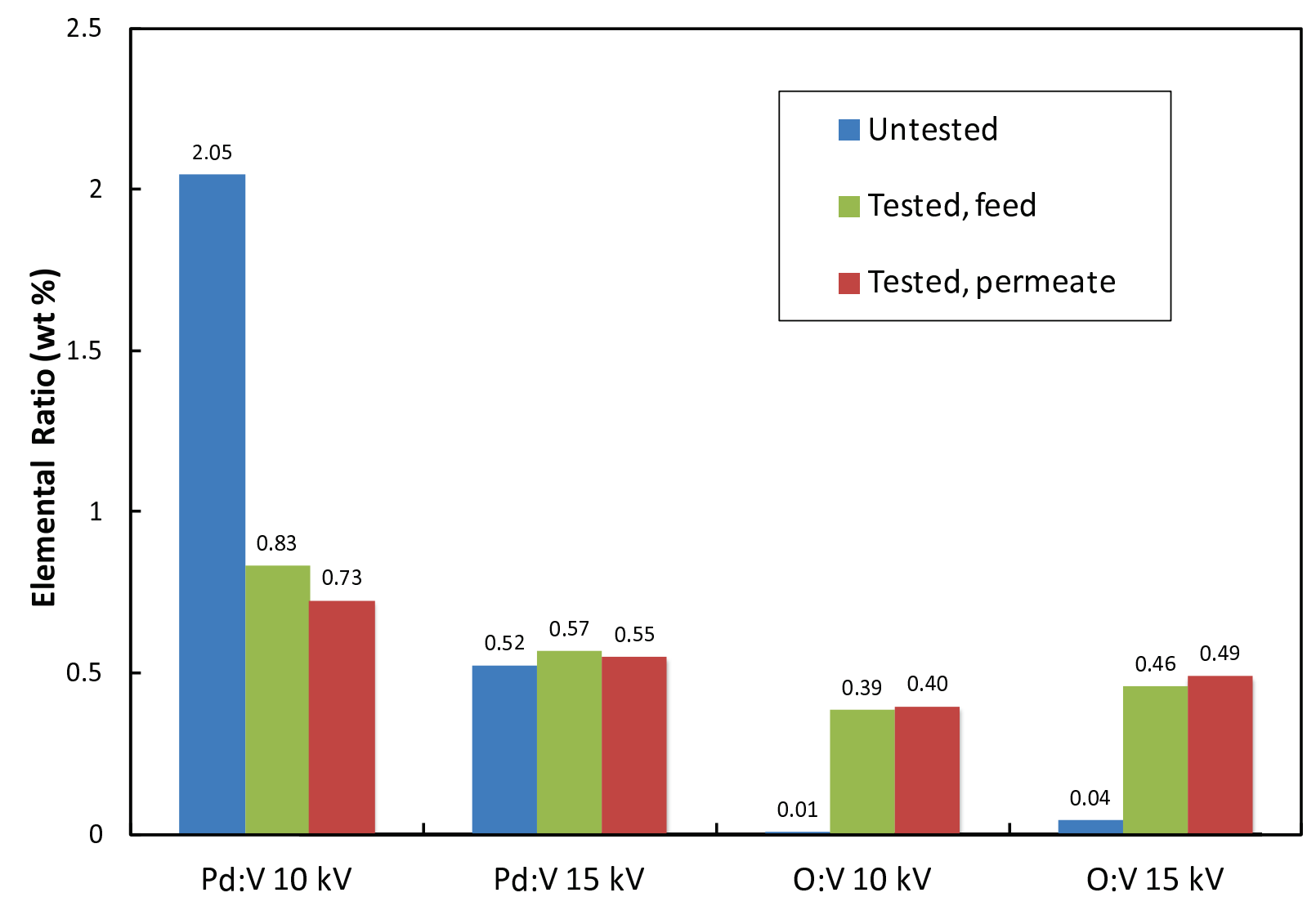


Figure 4

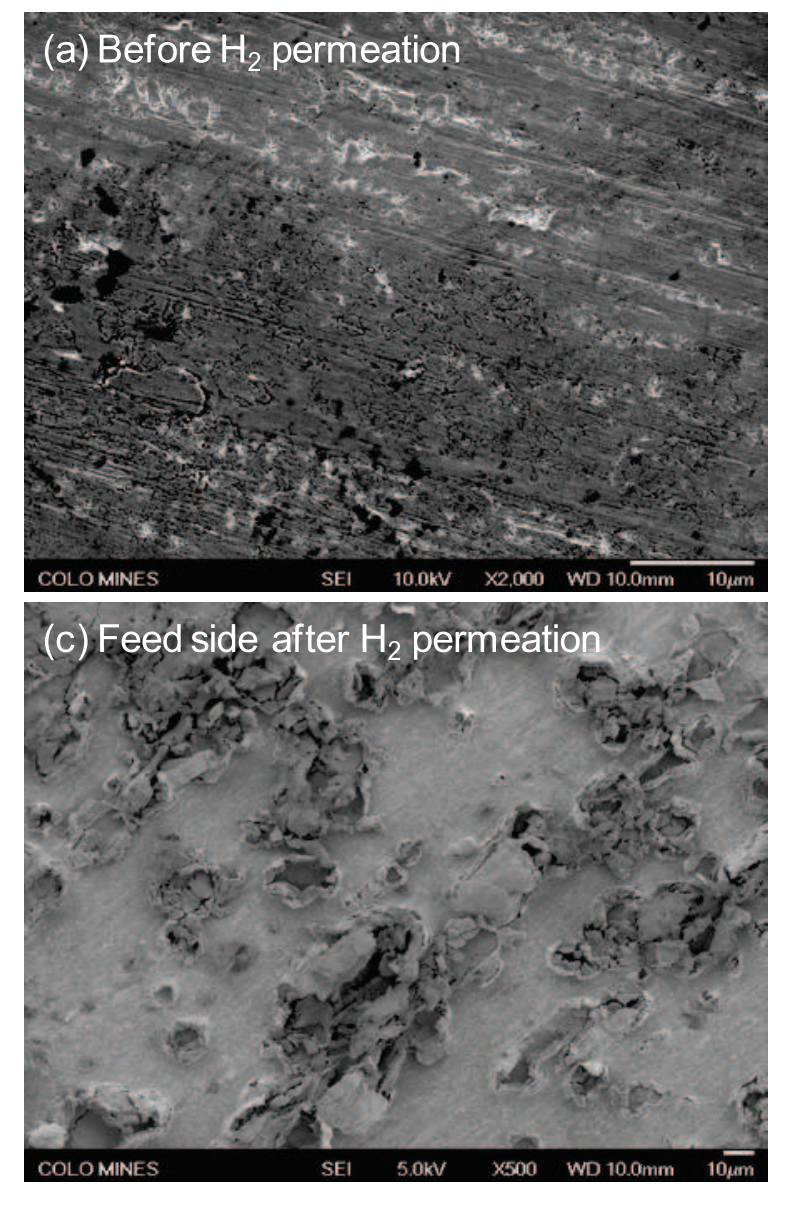

(b) Schematic of membrane deformation

Figure 5

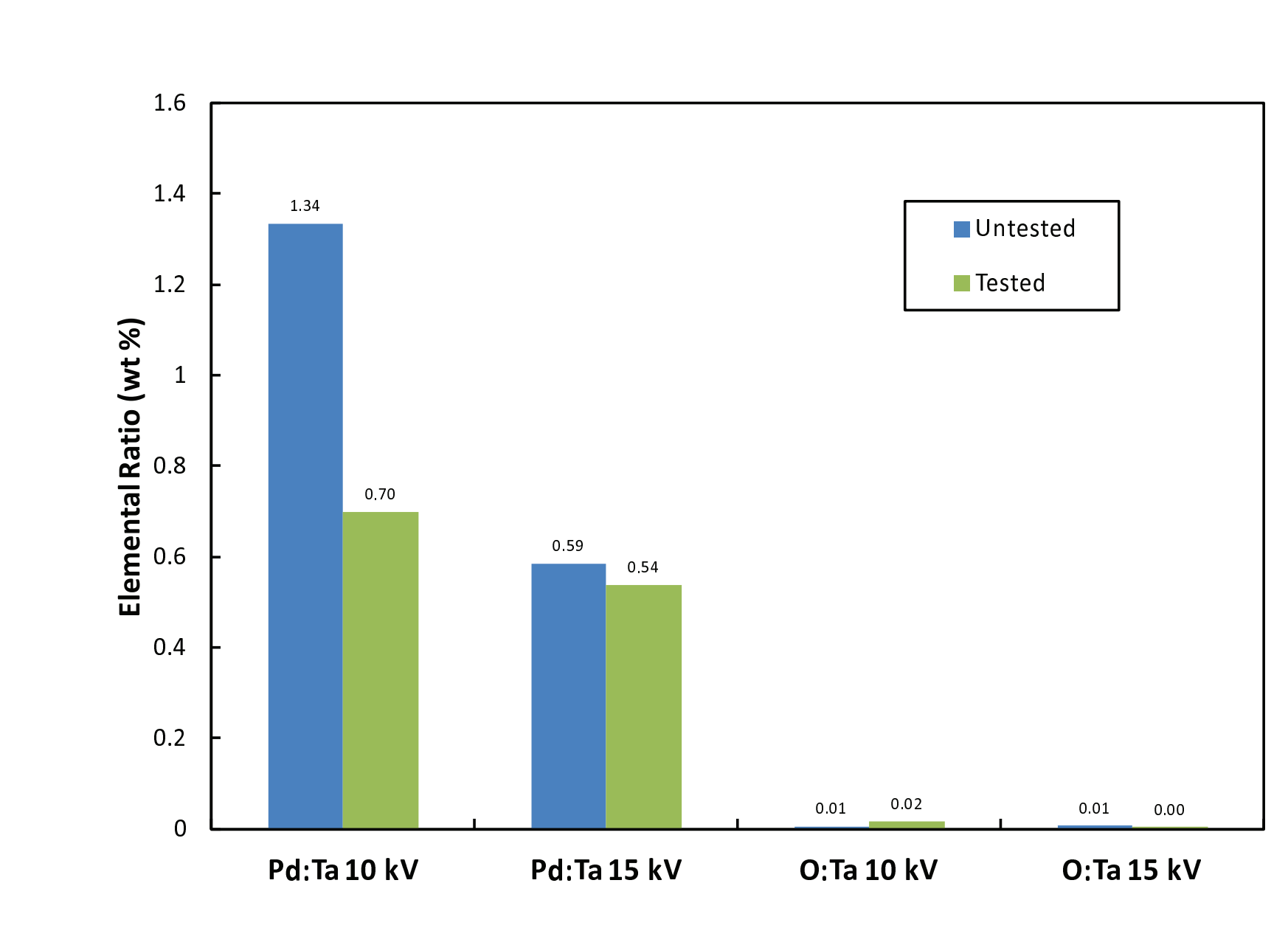

\section{Figure 5}

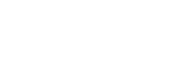

.
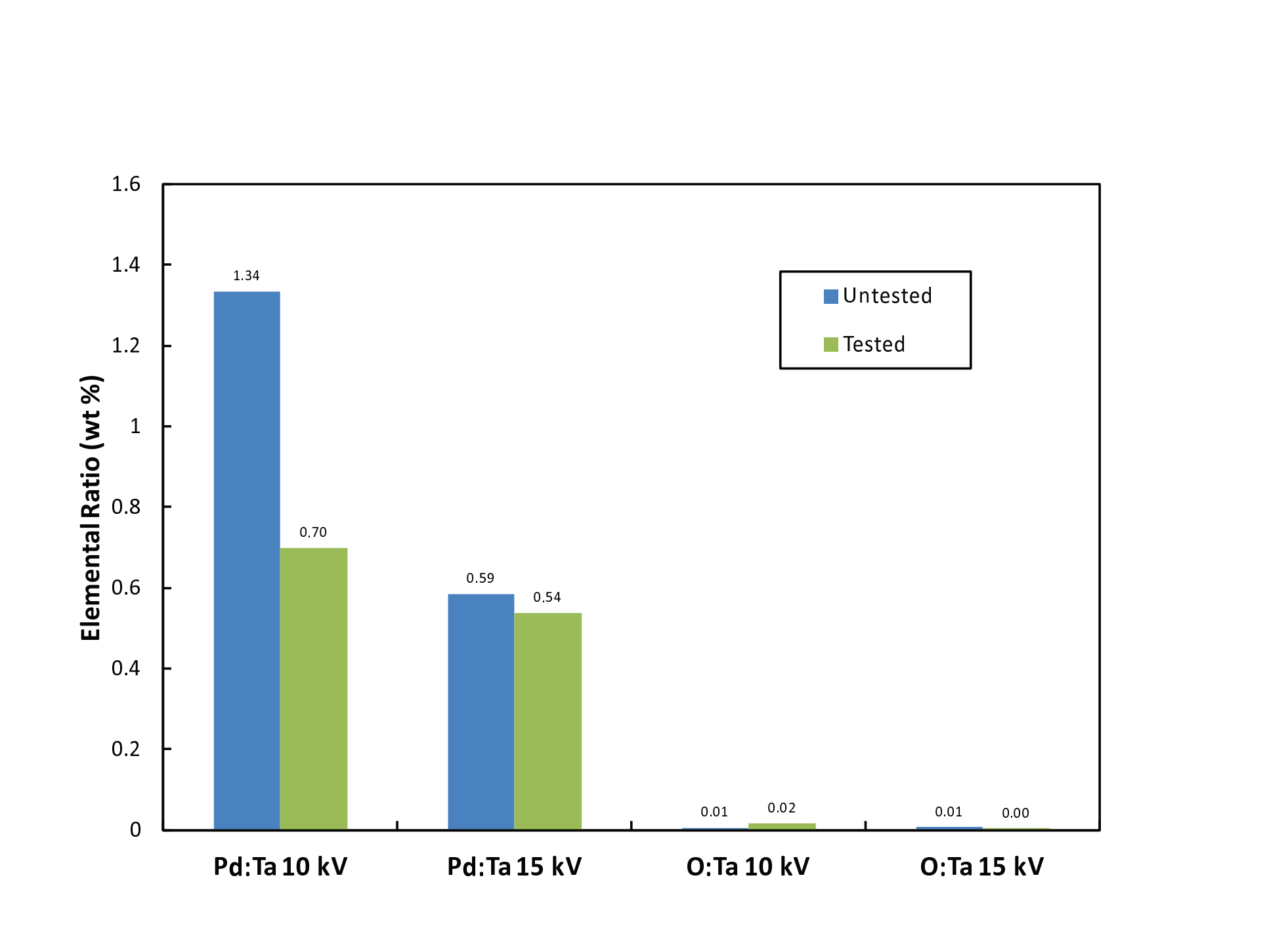
Figure 6

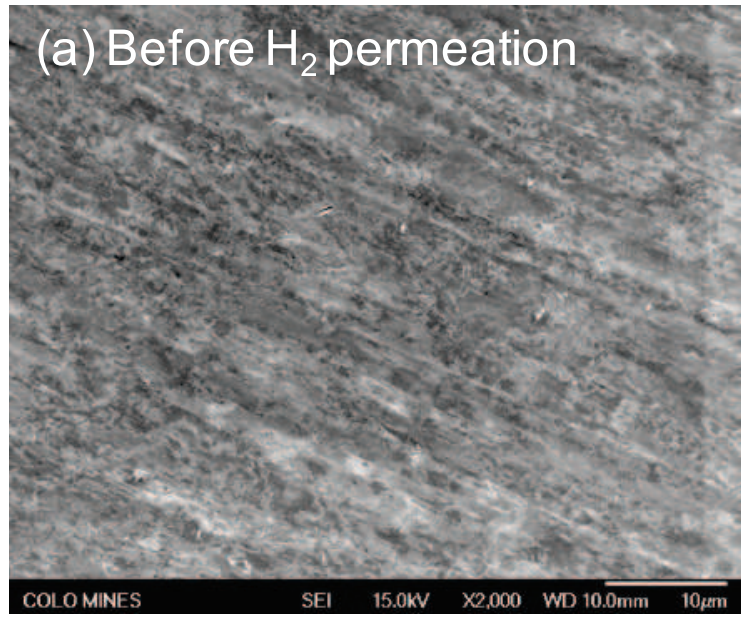

(b) Schematic of membrane deformation
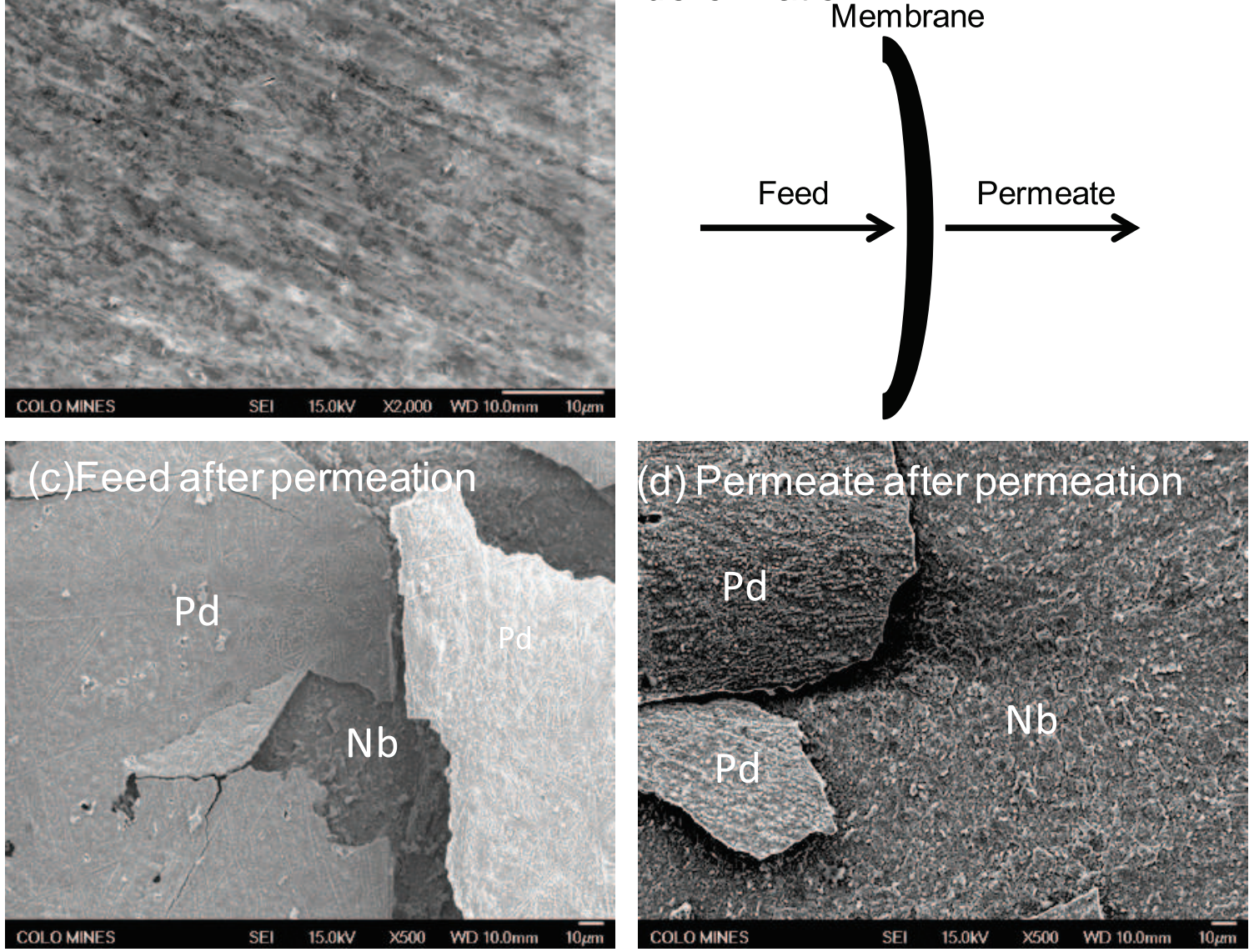
Figure 7

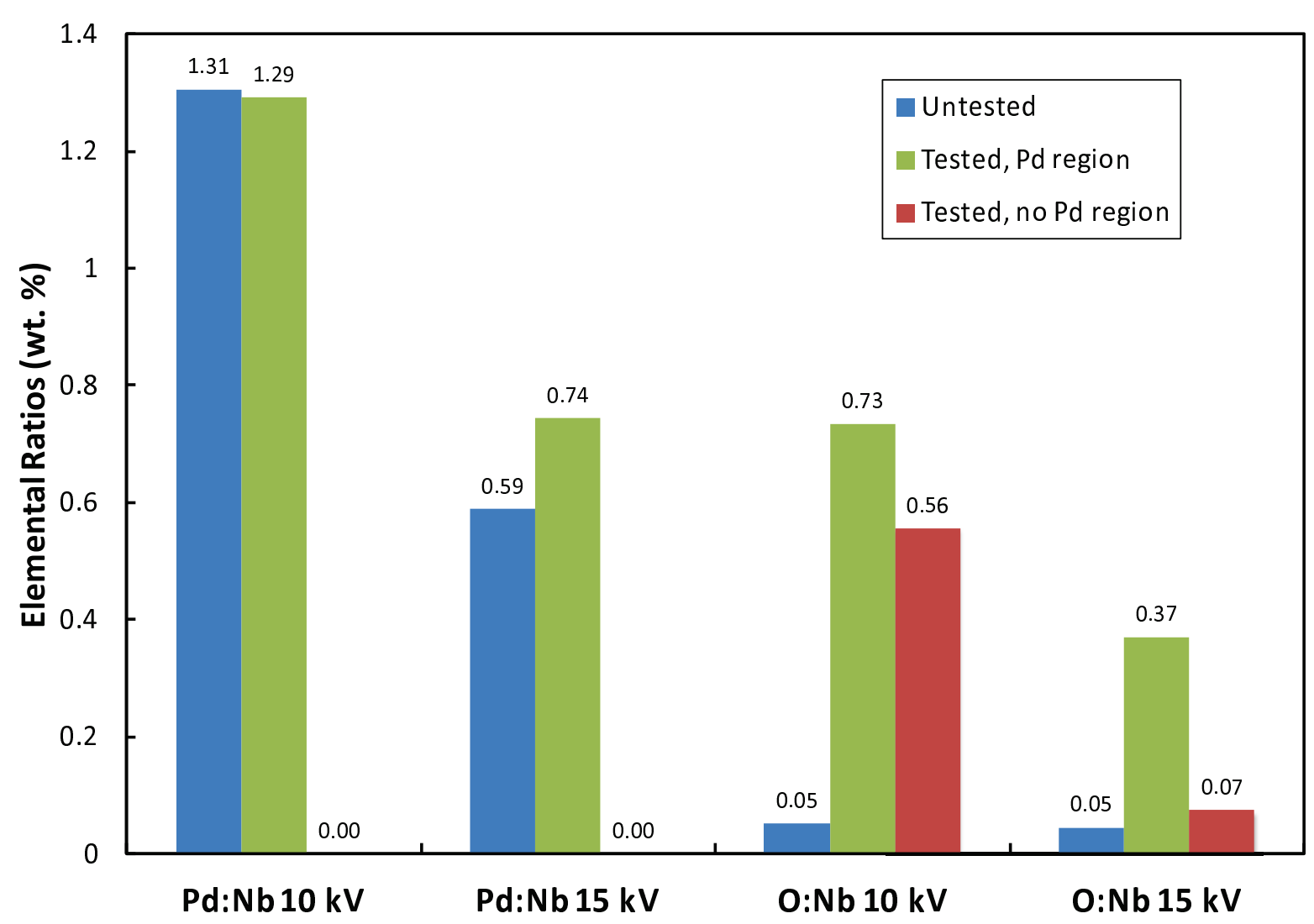

